\title{
TINGKAT PENGETAHUAN TENTANG SEKS BEBAS PADA REMAJA KELAS XI DI SMA NEGERI 11 YOGYAKARTA TAHUN 2014
}

\author{
Suherni ${ }^{1}$, Anita Rahmawati ${ }^{1}$ \\ 1Jurusan Kebidanan Poltekkes Kemenkes Yogyakarta, Jalan Mangkuyudan MJ III/304 Yogyakarta 55143, \\ Email: ksuherni@yahoo.com.
}

\section{ABSTRACT}

Background: Free sex has become more familiar to teenagers in today's life. This phenomenon occurs within many teenagers in junior and senior high schools, in big cities as well as in remote villages. Free sex may result in unwanted pregnancy, sexually transmitted infections, and social disruption in the society.

Objective: This study aimed to determine the level of knowledge about free sex in adolescents.

Methods: This research was conducted in April 2014, at SMA 11 Yogyakarta. The subjects were all students of class XI, consisted of 270 students. This study used a questionnaire as a measuring tool. Data analysis was performed with a univariate analysis.

Results: Results showed that most respondents had adequate level of knowledge (81\%), $17 \%$ had moderate level of knowledge and $2 \%$ have low level of knowledge about free sex.

Conclusion: The level of knowledge about free sex in SMA Negeri 11 Yogyakarta students was majority adequate.

Keywords: Knowledge Level, Teens, Free Sex

\section{PENDAHULUAN}

Remaja adalah suatu fase tumbuh kembang yang dinamis dalam kehidupan, merupakan periode transisi dari masa kanakkanak ke masa dewasa yang ditandai percepatan perkembangan fisik, mental, emosional, dan sosial. Masa remaja pada umumnya dimulai pada usia 10-13 tahun dan berakhir pada usia 18-22 tahun. ${ }^{(1)}$ Secara biologis alat reproduksi remaja sudah mencapai kematangan misalnya untuk remaja laki-laki sudah mengalami mimpi basah dan untuk perempuan sudah mengalami menstruasi. Sebagai remaja, mereka sudah mampu aktif secara seksual. Namun, remaja belum cukup mampu untuk membuat keputusan sendiri, oleh karena itu mereka sering terjerumus ke dalam kegiatankegiatan yang menyimpang dari aturan, salah satu contohnya adalah perilaku seks bebas. ${ }^{(2)}$
Data dari hasil survey Komisi Perlindungan Anak Indonesia (KPAI) di 33 provinsi dari Januari sampai Juli 2013 menunjukkan 62,7\% remaja SMP dan SMA tidak perawan. Badan Koordinasi Keluarga Berencana Nasional (BKKBN) menyebutkan hal yang sama bahwa terdapat $22,6 \%$ remaja menganut seks bebas. Dari data tersebut, ironisnya $21 \%$ di antaranya dilaporkan melakukan aborsi. ${ }^{(3)}$

Seks bebas menjadi hal yang sangat biasa bagi kalangan remaja saat ini. Tanpa merasa malu mereka meminta pasangannya untuk melakukan hal tersebut, hal yang sebenarnya dianggap tabu oleh masyarakat sekitar. Bukan hanya wanita dewasa saja yang melakukannya, namun sekarang kalangan remaja sudah melakukannya walaupun hanya satu kali. Kejadian ini menimpa remaja-remaja yang justru masih sekolah SMP dan SMA yang bukan hanya 
keberadaannya di kota-kota besar saja melainkan sudah sampai ke pelosok desa. ${ }^{(4)}$

\section{Data dari Perhimpunan Keluarga} Berencana Indonesia (PKBI) menunjukkan jumlah remaja usia 15 sampai 19 tahun di DIY tahun 2009 adalah 256.500 jiwa. Dari jumlah total remaja tersebut, lebih dari 600 jiwa melakukan konsultasi kehamilan yang meliputi juga konsultasi kehamilan tidak diinginkan. Menurut KRR SDKI tahun 2012, persentase perbandingan pria dan wanita yang melakukan hubungan seksual lebih tinggi pria dibanding wanita (8\%). Pria dengan tingkat pendidikan SMA atau lebih tinggi cenderung pernah melakukan hubungan seksual dibandingkan dengan pria yang tingkat pendidikannya lebih rendah. Akibat perilaku seks bebas tersebut, di provinsi D.I. Yogyakarta tahun 2009 tercatat sebanyak 946 orang terkena infeksi menular seksual, prevalensi tertinggi terdapat di Kota Yogyakarta, yaitu sebanyak 698 kasus. ${ }^{(5)}$

Studi pendahuluan di SMA Negeri 11 Yogyakarta, didapatkan hasil wawancara terhadap 10 siswa, hanya 5 orang yang tahu tentang pengertian seks bebas, bentukbentuk seks bebas, faktor yang mendorong seks bebas, dan dampak seks bebas, sedangkan 5 orang lainnya belum mengetahui tentang bentuk-bentuk seks bebas beserta faktor yang mendorong terjadinya seks bebas. Tujuan penelitian ini untuk mengetahui tingkat pengetahuan tentang seks bebas pada remaja kelas XI di SMA Negeri 11 Yogyakarta.

\section{BAHAN DAN CARA PENELITIAN}

Jenis penelitian ini adalah deskriptif kuantitatif dengan metode cross sectional. Populasi dalam penelitian ini adalah siswa kelas XI SMA Negeri 11 Yogyakarta sejumlah 270 siswa yang hadir dan bersedia menjadi responden. Penelitian ini dilaksanakan di SMA Negeri 11 Yogyakarta pada tanggal 9 April 2014. Variabel yang diteliti adalah tingkat pengetahuan remaja tentang seks bebas. Instrumen penelitian yang digunakan adalah kuesioner tertutup. Uji validitas dan reliabilitas dilakukan pada tanggal 30 Maret 2014 di SMA Negeri 10 Yogyakarta, sebanyak 36 siswa.

\section{HASIL DAN PEMBAHASAN}

Responden dengan jenis kelamin terbanyak adalah perempuan, pekerjaan ayah terbanyak adalah pegawai negeri, pekrjaan ibu terbanyak adalah ibu rumah tangga, dan media massa yang paling sering diakses adalah media siber, diterangkan pada tabel berikut:

Tabel 1. Distribusi Frekuensi Responden Berdasarkan Karakteristik di SMA Negeri 11 Yogyakarta

\begin{tabular}{cc}
\multicolumn{3}{c}{ Responden } \\
\hline Karakter & $\%$
\end{tabular}

Jenis kelamin

$\begin{array}{lcc}\text { a. Laki-laki } & 113 & 42 \\ \text { b. Perempuan } & 157 & 58 \\ \quad \text { jumlah } & 270 & 100 \\ \text { Pekerjaan Ayah } & & \end{array}$

a. Pegawai negeri $\quad 98 \quad 37$

b. Pegawai swasta $\quad 70 \quad 26$

$\begin{array}{lll}\text { c. Buruh } & 6 & 2\end{array}$

d. Wiraswasta $82 \quad 30$

e. Petani 220,7

f. Tidak bekerja $\quad 12 \quad 4,3$ $\begin{array}{lll}\text { jumlah } & 270 & 100\end{array}$

(Sumber: data primer 2014) 
Tabel 1. Distribusi Frekuensi Responden Berdasarkan Karakteristik di SMA Negeri 11 Yogyakarta (Lanjutan)

\begin{tabular}{|c|c|c|}
\hline \multirow[t]{2}{*}{ Karakter } & \multicolumn{2}{|c|}{ Responden } \\
\hline & f & $\%$ \\
\hline \multicolumn{3}{|l|}{ Pekerjaan ibu } \\
\hline a. Pegawai negeri & 52 & 19,3 \\
\hline b. Pegawai swasta & 34 & 12,6 \\
\hline c. Buruh & 16 & 5,9 \\
\hline d. Wiraswasta & 60 & 22,2 \\
\hline e. Petani & 1 & 0,4 \\
\hline a. Tidak bekerja & 107 & 39,6 \\
\hline jumlah & 270 & 100 \\
\hline \multicolumn{3}{|c|}{ Media massa yang sering diakses } \\
\hline a. Media cetak & 32 & 12 \\
\hline b. Media elektronik & 64 & 24 \\
\hline c. Media siber & 174 & 64 \\
\hline jumlah & 270 & 100 \\
\hline
\end{tabular}

Secara umum tingkat pengetahuan responden adalah baik, tercantum pada tabel berikut.

Tabel 2. Distribusi Frekuensi Responden berdasarkan Tingkat Pengetahuan tentang Seks Bebas di SMA Negeri 11 Yogyakarta

\begin{tabular}{|c|c|c|}
\hline \multirow{2}{*}{$\begin{array}{l}\text { Tingkat } \\
\text { pengetahuan }\end{array}$} & \multicolumn{2}{|c|}{ Responden } \\
\hline & & \\
\hline a. $\quad$ Baik & 220 & 81 \\
\hline b. Cukup & 45 & 17 \\
\hline c. kurang & 5 & 2 \\
\hline jumlah & 270 & 100 \\
\hline
\end{tabular}

(Sumber: data primer 2014)

Responden yang memiliki tingkat pengetahuan baik adalah responden dengan jenis kelamin perempuan. Responden dengan tingkat pengetahuan baik mayoritas ayah bekerja sebagai pegawai negeri, ibu tidak bekerja dan responden yang sering mengakses media siber.
Tabel 3. Distribusi Frekuensi Pengetahuan Tentang Seks Bebas Berdasarkan Karakteristik Responden Kelas XI di SMA Negeri 11 Yogyakarta

\begin{tabular}{lcccccc}
\hline \multirow{2}{*}{ Karakteristik } & \multicolumn{6}{c}{ Tingkat Pengetahuan } \\
\cline { 2 - 7 } & \multicolumn{3}{c}{ Baik } & \multicolumn{2}{c}{ Cukup } & \multicolumn{3}{c}{ Kurang } \\
\cline { 2 - 7 } & $\mathbf{f}$ & $\%$ & $\mathbf{f}$ & $\%$ & $\mathbf{f}$ & $\%$ \\
\hline Jenis Kelamin & & & & & & \\
a.Laki-Laki & 90 & 80 & 20 & 18 & 3 & 2 \\
b.Perempuan & 130 & 83 & 25 & 16 & 2 & 1 \\
$\quad$ Jumlah & 220 & & 45 & & 5 & \\
\hline
\end{tabular}

Tabel 3. Distribusi Frekuensi Pengetahuan Tentang Seks Bebas Berdasarkan Karakteristik Responden Kelas XI di SMA Negeri 11 Yogyakarta (Lanjutan)

\begin{tabular}{lccccccc}
\hline & \multicolumn{6}{c}{ Tingkat Pengetahuan } \\
\cline { 2 - 7 } \multicolumn{1}{c}{ Karakteristik } & \multicolumn{3}{c}{ Baik } & \multicolumn{2}{c}{ Cukup } & \multicolumn{3}{c}{ Kurang } \\
\cline { 2 - 7 } & $\mathbf{f}$ & \% & f & f & $\%$ \\
\hline Pekerjaan Ayah & & & & & & \\
a. Pegawai Negeri & 79 & 81 & 17 & 17 & 2 & 2 \\
b. Pegawai Swasta & 56 & 80 & 12 & 17 & 2 & 3 \\
c. Buruh & 4 & 67 & 2 & 33 & - & - \\
d. Wiraswasta & 71 & 87 & 11 & 13 & - & - \\
e. Petani & 2 & 100 & - & - & - & - \\
f. Tidak Bekerja & 8 & 67 & 3 & 25 & 1 & 8 \\
$\quad$ Jumlah & 220 & & 45 & & 5 & \\
Pekerjaan Ibu & & & & & & \\
a. Pegawai Negeri & 42 & 81 & 9 & 17 & 1 & 2 \\
b. Pegawai Swasta & 25 & 74 & 7 & 20 & 2 & 6 \\
c. Buruh & 11 & 69 & 4 & 25 & 1 & 6 \\
d. Wiraswasta & 53 & 88 & 6 & 10 & 1 & 2 \\
e. Petani & 1 & 100 & - & - & - & - \\
f. Tidak Bekerja & 88 & 82 & 19 & 18 & - & - \\
$\quad$ Jumlah & 220 & & 45 & & 5 & \\
Media Massa & & & & & & \\
b. Media Cetak & 25 & 78 & 6 & 19 & 1 & 3 \\
c. Media Elektronik & 53 & 83 & 11 & 17 & - & - \\
d. Media Siber & 142 & 82 & 28 & 16 & 4 & 2 \\
$\quad$ Jumlah & 220 & & 45 & & 5 & \\
\hline
\end{tabular}

(Sumber: data primer 2014)

Secara umum tingkat pengetahuan seks bebas remaja kelas XI di SMA Negeri 11 Yogyakarta dalam kategori baik yaitu $81 \%$, meskipun masih diperoleh $17 \%$ siswa dalam kategori cukup, dan 2\% dalam kategori rendah. Hal ini dimungkinkan karena sebagian siswa-siswi sebagian besar telah memperoleh informasi tentang seks bebas 
melalui berbagai informasi baik dari media massa maupun dari orangtua dan guru.

Secara khusus karakteristik remaja kelas XI di SMA Negeri 11 Yogyakarta adalah $58 \%$ perempuan dan $48 \%$ laki-laki. Berdasarkan pekerjaan ayah $37 \%$ responden memiliki ayah dengan pekerjaan pegawai negeri, sedangkan menurut pekerjaan ibu $39,6 \%$ responden memiliki ibu yang tidak bekerja atau sebagai ibu rumah tangga. Karakteristik remaja berdasarkan media massa yang paling sering diakses terbanyak adalah media siber yaitu sebesar 64\%.

Hasil penelitian menunjukkan bahwa tingkat pengetahuan yang baik tentang seks bebas pada remaja kelas XI di SMA Negeri 11 Yogyakarta ditinjau dari jenis kelamin lebih banyak prosentase pada jenis kelamin perempuan yaitu sebesar $83 \%$, sedangkan laki-laki hanya $80 \%$. Secara teoritis jenis kelamin merupakan salah satu faktor genetik yang memengaruhi seseorang untuk berperilaku khususnya dalam perilaku kesehatan. Menurut hasil dari penelitian, pengetahuan laki-laki dan perempuan lebih baik pengetahuan perempuan tentang seks bebas, ini dikarenakan perempuan lebih menjaga kesehatan reproduksinya daripada laki-laki karena secara umum perempuan lebih rawan terkena penyakit sistem reproduksi.

Sedangkan tingkat pengetahuan tentang seks bebas pada remaja ditinjau dari pekerjaan ayah pengetahuan baik adalah pada ayah yang bekerja wiraswasta dan petani yaitu sebesar $87 \%$ dan 100\%, sedangkan yang berpengetahuan kurang pada ayah yang tidak bekerja $8 \%$. Tingkat pengetahuan tentang seks bebas pada remaja ditinjau dari pekerjaan ibu untuk kategori pengetahuan baik adalah pada responden yang memiliki ibu bekerja wiraswasta dan petani yaitu sebesar $88 \%$ dan $100 \%$, sedangkan yang berpengetahuan kurang pada responden yang memiliki ibu bekerja sebagai pegawai swasta dan buruh yaitu sebesar $6 \%$. Secara teori, lingkungan pekerjaan dapat menjadikan seseorang untuk memperoleh pengalaman dan pengetahuan baik secara langsung maupun secara tidak langsung.

Tingkat pengetahuan remaja ditinjau dari media massa yang paling sering diakses memiliki kategori baik adalah mereka yang media siber yaitu sebesar $82 \%$ dan yang memiliki pengetahuan kategori kurang adalah yang mengakses media cetak yaitu sebesar $3 \%$. Menurut teori, media massa adalah faktor lingkungan yang mengubah perilaku khalayak melalui proses pelaziman klasik, pelaziman operan, atau proses imitasi (belajar sosial) (Rakhmat, 2001). ${ }^{(6)}$ Dua fungsi dari media massa adalah media massa memenuhi kebutuhan akan fantasi dan informasi. Dari penelitian ini didapat pengetahuan baik terdapat pada mereka yang mengakses media siber. Melalui media siber mereka dapat memperoleh informasi lebih banyak dari media cetak atau media elektronik. Media siber menyediakan banyak 
kemudahan dan apa yang akan kita cari dengan mudah dapat ditemukan. Dengan demikian, responden dapat dengan mudah mendapatkan informasi khususnya informasi tentang seks bebas melalui media siber.

Berdasarkan hasil tersebut maka peneliti menyatakan bahwa pengetahuan tentang seks bebas pada remaja kelas XI di SMA Negeri 11 Yogyakarta dalam kategori baik. Hasil penelitian ini sesuai dengan penelitian yang pernah dilakukan sebelumnya oleh Susi Erna Wati pada tahun 2011 dengan judul "Tingkat Pengetahuan Siswa-siswi tentang seks bebas bebas di SMK PGRI 3 Kediri". ${ }^{7}$

\section{KESIMPULAN}

Tingkat pengetahuan tentang seks bebas pada siswa kelas XI SMA Negeri 11 Yogyakarta adalah baik. Menurut karakteristik responden, sebagian besar responden berjenis kelamin perempuan. Pekerjaan ayah sebagian besar bekerja sebagai pegawai negeri sedangkan pekerjaan ibu sebagian besar sebagai ibu rumah tangga, sedangkan media massa yang paling sering diakses adalah media siber. Tingkat pengetahuan tentang seks bebas menurut jenis kelamin dalam kategori baik mayoritas adalah perempuan, sedangkan tingkat pengetahuan tentang seks menurut pekerjaan ayah dan ibu dalam kategori baik adalah wiraswasta dan pengetahuan tentang seks bebas dalam kategori baik menurut media massa yang paling sering diakses adalah media siber. Diharapkan untuk kepala sekolah dan guru
SMA Negeri 11 Yogyakarta bisa menambah materi pelajaran tentang kesehatan reproduksi remaja dan psikologi seksual remaja pada pelajaran muatan lokal, serta melakukan kerjasama lintas sektoral dengan Dinas Kesehatan atau Puskesmas. Hendaknya guru bimbingan konseling mengkhususkan dan memberikan contoh antara lain program etika yang baik dalam pergaulan bagi semua siswa, memantau buku-buku bacaan siswa yang bermuatan pornografi, serta melibatkan orang tua sebagai fasilitator bagi remaja. Pihak sekolah seperti kepala sekolah dan guru bimbingan konseling memberikan informasi kepada orang tua siswa tentang betapa pentingnya membahas seksualitas pada anak remajanya khususnya untuk kasus seks bebas dan pergaulan bebas.

\section{KEPUSTAKAAN}

1. Sarwono, S. W. Psikologi Remaja. Jakarta :PT Raja Grafindo Persada. 2007.

2. Notoatmodjo, S. IImu Perilaku Kesehatan. Jakarta : Rineke Cipta. 2010.

3. Badan Pusat Statistik Jakarta, Badan Koordinasi Keluarga Berencana Nasional Jakarta, Departemen Kesehatan Jakarta, Macro Internasional Maryland USA. Survei Kesehatan Reproduksi Remaja Indonesia 2007. Jakarta: BPS dan Macro Internasional.

4. BKKBN.. Remaja dan Seks Pranikah. 2008. Diunduh tanggal 24 Januari 2015. Pukul 01.00 WIB. 
$<$ www.bkkbn.go.id.webdetailrubrik.phpMyl

$\mathrm{D}=518$.pdf. $>$

5. Kemenkes RI. Survei Demografi dan Kesehatan Remaja. 2012.

6. Rakhmat, Jalaludin. Metode Penelitian Komunikasi. Bandung : PT Remaja Rosdakarya. 2001.

7. Erna, Susi. Tingkat Pengetahuan SiswaSiswi Tentang Seks Bebas di SMK PGRI 3 Kediri. KTI. Kediri : UNP Kediri. 2011. 